\title{
Paraquat induced pulmonary fibrosis in three survivors
}

\author{
M Hudson, S B Patel, S W B Ewen, C C Smith, J A R Friend
}

\begin{abstract}
Pulmonary lesions following paraquat poisoning are believed to be almost invariably fatal. The three patients reports here survived despite persistent radiological change. One of the patients died after taking a larger dose of paraquat one year later, and at necropsy histological changes attributable to the two episodes of paraquat poisoning were apparent.
\end{abstract}

The ingestion of a large dose of paraquat (over $40 \mathrm{mg}$ paraquat ion $/ \mathrm{kg}$ body weight) invariably proves fatal. ${ }^{1}$ Less severe poisoning (20$40 \mathrm{mg}$ paraquat ion $/ \mathrm{kg}$ body weight) is fatal in most cases, but death may be delayed by weeks, the ultimate cause usually being lung damage characterised by pulmonary fibrosis. ${ }^{2}$

Lung damage was initially thought to imply a fatal outcome. ${ }^{3}$ Survivors have, however, been reported who have developed varying degrees of lung damage, ranging from transient pleural effusions ${ }^{4}$ and resolving pulmonary infiltrates ${ }^{5}$ to persistent radiological change. ${ }^{6}$

We report three patients with persistent radiological pulmonary change after ingesting Gramoxone (200 g/1,20\% paraquat), all of whom survived for over 12 months. One of these patients, however, subsequently died from a larger dose of paraquat and at necropsy the histological changes attributable to the two episodes were apparent.

\section{Case reports}

CASE 1

A healthy 21 year old woman, a non-smoker, attempted suicide by swallowing about $15 \mathrm{ml}$ of Gramoxone. She developed vomiting five hours later and was admitted at 72 hours with severe buccal and oral ulceration. She was dehydrated, with a slight fever, but had no other signs.

In the initial investigation the abnormal results included a white cell count of $15.5 \times$ $10^{9} / 1$ (90\% neutrophils); serum sodium 120 $\mathrm{mmol} / \mathrm{l}$, potassium $2.2 \mathrm{mmol} / \mathrm{l}$, urea 19.6 $\mathrm{mmol} / \mathrm{l}$, and creatinine $434 \mathrm{mmol} / \mathrm{l}$. Microscopic examination of urine showed red blood cells in addition to hyaline and cellular casts. The urinary paraquat concentration five days after ingestion was $0.8 \mu \mathrm{g} / \mathrm{ml}$. The initial spirometric values, arterial blood gases, liver function, and chest radiograph were within normal limits.

The acute renal failure improved with supportive management, the glomerular filtration rate rising from 15 to $94 \mathrm{ml} / \mathrm{min}$. The mouth ulceration resolved completely.

The first evidence of lung damage was an asymptomatic reduction in transfer factor for carbon monoxide (TLCO) 14 days after ingestion, followed by breathlessness during exertion at 21 days. The chest radiograph then showed fine linear shadowing in both upper zones. The patient was started on oral prednisolone $20 \mathrm{mg}$ daily, which was reduced over five weeks; her breathlessness and pulmonary function improved (table) but the radiological changes persisted.

A year later she swallowed $60 \mathrm{ml}$ of Gramoxone. On admission to hospital six hours later, her urinary paraquat concentration was $14000 \mu \mathrm{g} / \mathrm{ml}$. She developed acute renal failure with hepatic damage and jaundice. Despite gastric lavage, Fuller's earth haemoperfusion, and haemodialysis she became increasingly tachypnoeic, with progressive radiological shadowing through-

Lung function measurements in the three patients

\begin{tabular}{|c|c|c|c|c|c|c|}
\hline \multirow[b]{2}{*}{ Patient No } & \multirow{2}{*}{\multicolumn{2}{|c|}{$\begin{array}{l}\text { Respiratory variable } \\
\text { (with predicted normal value) }\end{array}$}} & \multicolumn{4}{|c|}{ Respiratory function value (weeks after paraquat ingestion) } \\
\hline & & & $\overline{2}$ & 4 & 8 & 52 \\
\hline $\begin{array}{l}1 \\
2 \\
3\end{array}$ & $\mathrm{FEV}_{1}(\mathbf{l})$ & $\begin{array}{l}(3 \cdot 15) \\
(2 \cdot 3) \\
(2 \cdot 6)\end{array}$ & $\frac{2.65}{1.00}$ & $\begin{array}{l}2 \cdot 60 \\
1 \cdot 10 \\
1 \cdot 10\end{array}$ & $\begin{array}{l}3.05 \\
1.40 \\
1.64\end{array}$ & $\begin{array}{l}3 \cdot 40 \\
2 \cdot 00 \\
1 \cdot 30\end{array}$ \\
\hline $\begin{array}{l}1 \\
2 \\
3\end{array}$ & FVC (1) & $\begin{array}{l}(3 \cdot 5) \\
(2 \cdot 7) \\
(2.9)\end{array}$ & $\frac{2.80}{1.05}$ & $\begin{array}{l}2 \cdot 60 \\
1 \cdot 40 \\
1 \cdot 10\end{array}$ & $\begin{array}{l}3.25 \\
1.80 \\
1 \cdot 70\end{array}$ & $\begin{array}{l}3 \cdot 70 \\
2 \cdot 50 \\
1 \cdot 35\end{array}$ \\
\hline $\begin{array}{l}1 \\
2 \\
3\end{array}$ & $\begin{array}{l}\text { Tlco } \\
(\mathrm{ml} / \mathrm{min} / \mathrm{kPa})\end{array}$ & $\begin{array}{l}(9 \cdot 7) \\
(7 \cdot 7) \\
(8 \cdot 1)\end{array}$ & $\frac{6.90}{\star}$ & $\begin{array}{l}8 \cdot 25 \\
3 \cdot 40 \\
\star\end{array}$ & $\begin{array}{l}7 \cdot 90 \\
4 \cdot 0 \\
4 \cdot 4\end{array}$ & $\begin{array}{l}8 \cdot 55 \\
5 \cdot 20 \\
4 \cdot 20\end{array}$ \\
\hline
\end{tabular}




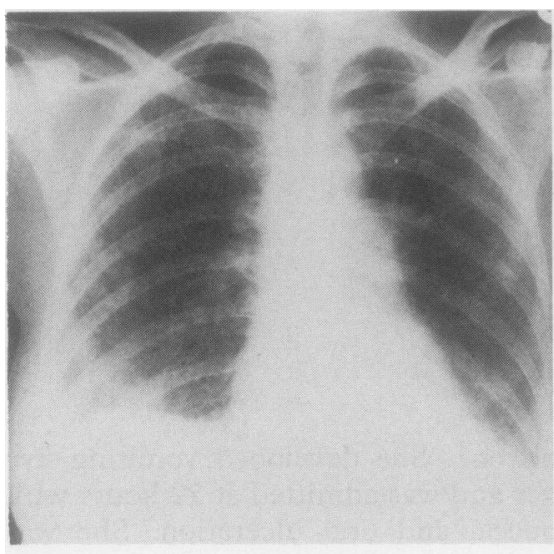

(a)

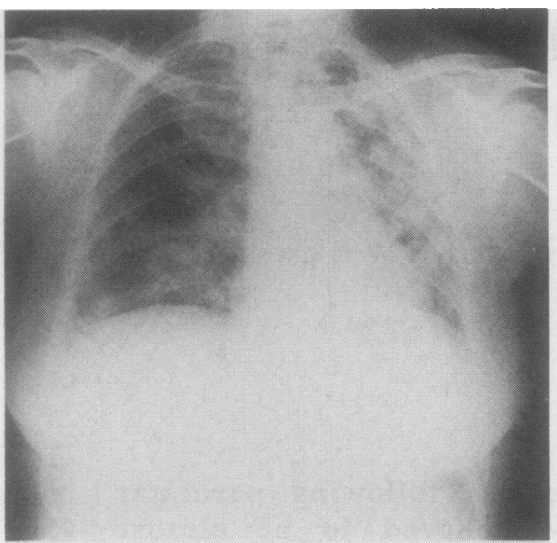

(b)

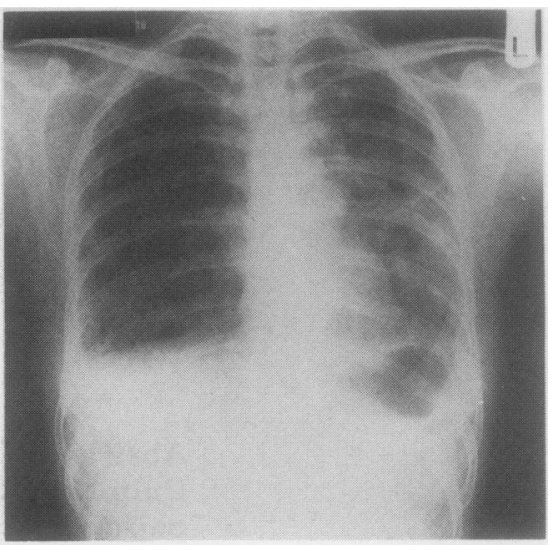

(c) out both lungs (fig 1a), and died 10 days after admission.

At necropsy the lungs were consolidated and together weighed $1860 \mathrm{~g}$. When they were sectioned severe haemorrhages were noted throughout and the subpleural zone showed pronounced fibrous thickening, particularly in the upper lobes. Histologically, the acute changes attributed to paraquat included widespread, almost confluent intra-alveolar haemorrhage, reticulated oedema, and proliferation of intra-alveolar macrophages, some being fused to form giant cells. Interstitial changes were limited to patchy oedema with early variable fibrosis. Disruption of alveolar walls had occurred to produce irregular air spaces lined by fibrin or hyaline membranes, and bronchopneumonia was present. The histological changes attributed to the first ingestion of paraquat consisted of pronounced subpleural thickening up to $3 \mathrm{~mm}$ in width, composed almost entirely of smooth muscle (fig 2). Distorted terminal bronchioles embedded in the smooth muscle contained polymorphonuclear leucocytes and were surrounded by lymphocytes.

\section{CASE 2}

A 52 year old nurse developed increasing exertional breathlessness with a dry, irritating cough over four to five weeks. She was unable to climb stairs and friends noticed that she was cyanosed. Her colleagues persuaded her to have a chest radiograph, which ultimately led to her admission.

On examination crepitations were audible over the left upper lobe and a chest radiograph showed extensive patchy opacification throughout the left lung and in the right lower zone (fig $1 b$ ). A routine chest radiograph two years before had been normal. At this point she admitted that five weeks previously she had accidentally swallowed a mouthful of weedkiller, later identified as Gramoxone, which had been stored in a "coke" bottle. She spat it out immediately but 24 hours later developed vomiting, diarrhoea, and a sore throat lasting for three days.

On admission her urea and creatinine concentrations and liver function were within normal limits. As she remained breathless she was treated with oral prednisolone $30 \mathrm{mg}$ daily, which was reduced over five weeks, and she gradually improved. Sequential pulmonary function tests over the following year showed progressive improvement (table). The initial radiological changes improved but at one year some residual fibrosis persisted.

\section{CASE 3}

A 41 year old housewife, who had had an episode of acute pigeon fancier's lung 12 years previously, was admitted with a seven day history of vomiting, diarrhoea, and a retrosternal burning sensation when she swallowed. She had had a persistent unproductive cough since her episode of pigeon fancier's

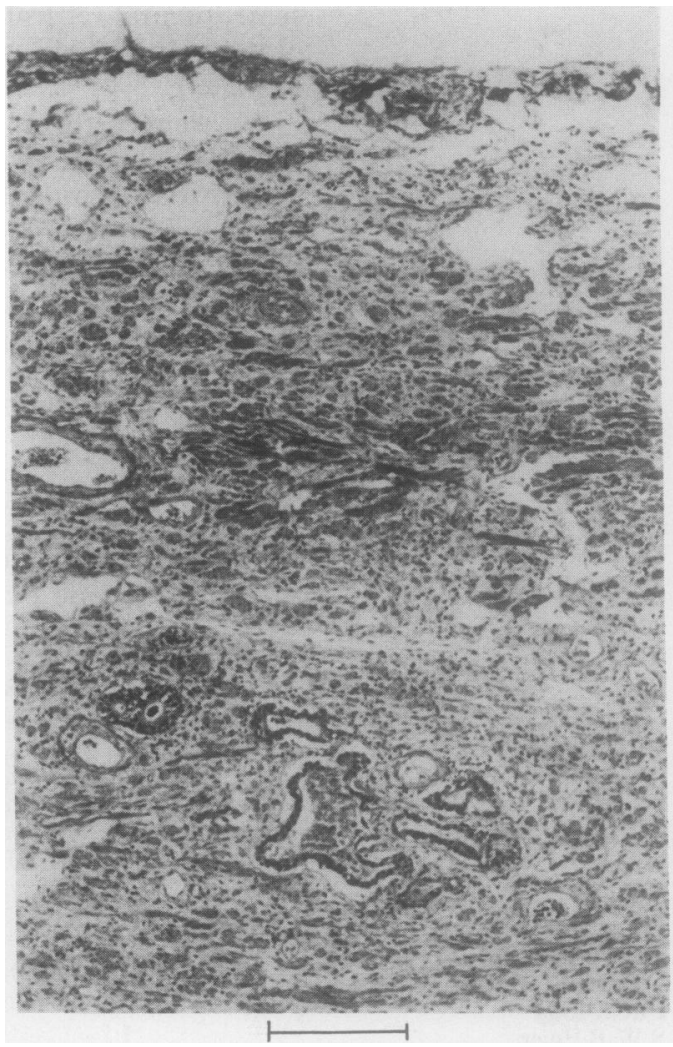

Figure 2 Histological changes in the lung attributed to the first ingestion of paraquat in patient 1 . The subpleural zone displays pronounced thickening composed of bundles of smooth muscle cells derived from blood vessels. Trapped bronchioles are distorted and contain red blood cells and macrophages. The scale bar represents $120 \mu \mathrm{m}$. 
lung. She was pale and dehydrated, with a small superficial ulcer on the buccal mucosa, but was otherwise normal. Her urine output was good (over $20 \mathrm{ml} / \mathrm{h}$ ) but her blood urea on admission was $43.5 \mathrm{mmol} / \mathrm{l}$ and serum creatinine $732 \mu \mathrm{mol} / 1$. The urine contained granular, hyaline, and red cell casts.

After intravenous rehydration, the urea concentration had fallen to $8.2 \mathrm{mmol} / 1$ and creatinine to $118 \mu \mathrm{mol} / 1$ on the sixth day after admission, and the casts cleared from the urine. A chest radiograph on admission was normal. Severe ulceration of the distal oesophagus was seen after a barium meal and confirmed at endoscopy; candidiasis was excluded by biopsy. On direct questioning, she denied the ingestion of any caustic substance or paraquat. She gradually became increasingly breathless on effort. A repeat chest radiograph 14 days after admission showed diffuse changes in the left lung field and right lower zone. Pulmonary function tests showed a severe restrictive defect (table); she was too dyspnoeic to perform the single breath TLco test. She then admitted having swallowed about $15 \mathrm{ml}$ of Gramoxone with suicidal intent seven days before admission. A psychiatric assessment confirmed a depressive illness and she began treatment with anafranil.

A reducing course of oral prednisolone, starting at $30 \mathrm{mg}$ daily, was given over six weeks. Her breathlessness and pulmonary function improved (table), but one year later breathlessness limited her walking to $100 \mathrm{~m}$ on the level. She still has a restrictive ventilatory defect and impaired gas exchange. Her chest radiograph currently shows some clearing of the right lung changes but residual fibrosis and loss of volume in the left lung (fig $1 c$ ).

\section{Discussion}

Only eight cases of survival of paraquat intoxication with radiological change have been reported. ${ }^{4-9}$ The appearances described range from pulmonary oedema ${ }^{7}$ and widespread interstitial and intra-alveolar shadowing ${ }^{8}$ to radiological changes suggestive of pulmonary fibrosis persisting for six months or more in the three survivors reported by Fock and Chan. ${ }^{6}$

Our first patient presents the unique case of two separate injuries to the lungs following repeated paraquat ingestion. On the first occasion a smaller dose of paraquat resulted in mild breathlessness, with functional and radiological changes that had improved over the year of follow up. The second dose was larger and lethal, with postmortem changes attributable to the two episodes, which were separated by 12 months.

At postmortem examination in the first case there was evidence of subpleural thickening consisting of pronounced smooth muscle proliferation, presumably derived from hyperplasia of vascular and airway smooth muscle. The location of the subpleural mature smooth muscle, with incorporation of bronchioles, indicates that the appearances are due to the previous pulmonary paraquat injury. ${ }^{1011}$ The second paraquat ingestion caused acute changes consisting of intra-alveolar haemorrhage and oedema with early interstitial fibrosis. Previous necropsy reports of survivors for five to eight days after paraquat ingestion describe identical features and pronounced subpleural fibrosis, ${ }^{12}$ although this was not evident in patient 1 , in whom subpleural mature smooth muscle was the dominant feature.

The toxic effects of paraquat on the lung are not fully explained but paraquat is now known to accumulate selectively in lung tissue. ${ }^{13}$ In addition, it undergoes a nicotinamide adenine dinucleotide phosphate dependent one electron reduction to form its free radical, which reacts with molecular oxygen to reform the cation and produce a superoxide anion; this is then believed to mediate the toxic effects on the lung. ${ }^{2}$

The number of fatalities in the United Kingdom from paraquat poisoning over the 10 years 1966-75 increased from one to 43 cases a year, with a rapid increase between 1971 and 1975 . Numbers of fatalities have not changed significantly since then, 31 being recorded in $1984 .^{14}$

Paraquat poisoning should be considered in the differential diagnosis of patients who have unexplained renal failure or progressive pulmonary changes-particularly if there is a history of a persistent sore throat and mouth or unexplained painful dysphagia. Shortly after paraquat ingestion adsorbents and purging may be of value, but once the changes are established there is no clear evidence that any treatment is helpful. The various treatments that have been tried include lung transplantation $^{15}$ but changes developed in the transplanted lung, suggesting paraquat damage, and the patient died after two weeks. Immunosuppresants, ${ }^{16}$ colchicene, ${ }^{17}$ and radiotherapy ${ }^{18}$ have also been used, but in the patients who recovered it has always been difficult to assess the contribution of the treatment.

Prednisolone was given to our three patients but without clear indication of benefit. Nevertheless, the confirmation that paraquat lung is not invariably fatal is encouraging. We suggest that all patients who have evidence of paraquat poisoning should be monitored for deterioration in pulmonary function for up to a month after ingestion, as evidence of pulmonary damage may not develop for several weeks.

We are grateful to Professor J M Stowers for permission to report case 1, and to Mrs B Calder for secretarial help.

1 Vale JS, Meredith JJ, Bucksby BM. Paraquat poisoning: Clinical features and immediate general management. Clinical features and im

2 Smith LL. Mechanism of paraquat toxicity in lung and its relevance to treatment. Hum Toxicol 1987;6:31-6.

3 Cooke NT, Flenley DC, Matthew H. Paraquat poisoning. QJM 1973;42:683-92.

4 Fisher HK, Humphries M, Bails R. Paraquat poisoning. Recovery from renal and pulmonary damage. Ann Intern Recovery from renal

5 Higgenbottam T, Crome P, Parkinson C, Nunn J. Further clinical observations on the pulmonary effects of paraquat ingestion. Thorax 1979;34:161-5.

6 Fock KM, Chan HC. Paraquat poisoning is not always fatal. Singapore Med J 1980;5:703-7.

7 Gardiner AJS. Pulmonary oedema in paraquat poisoning. Thorax 1972;27:132-5.

8 Hendy MS, Williams PS, Ackrill P. Recovery from severe 
pulmonary damage due to paraquat administered intravenously and orally. Thorax 1984;39:874-5.

9 Jones GR, Owen-Lloyd P. Recovery from poisoning by $20 \%$ paraquat. Br J Clin Pract 1973;27:69-70.

10 Anderson AE, Foraker AG. Morphological aspects of interstitial pulmonary fibrosis. Arch Pathol 1960;70:79-93.

11 Liebow A, Loring WE, Felton WL. Musculature of the lungs in chronic pulmonary disease. Am J Pathol 1953;
lise 29:885-912.

12 Parkinson $\mathrm{C}$. The changing pattern of paraquat poisoning in man. Histopathology 1980;4:171-83.

13 Rose MS, Lock EA, Smith LL, Wyatt J. Paraquat accumulation in tissue and species specificity. Biochem Pharmacol 1976;25:419-23.
14 Guyon LJ, Volans GN. The epidemiology and prevention of paraquat poisoning. Hum Toxicol 1987;6:19-29.

15 Matthew H, Logan A, Woodruff MFA, Heard B. Paraquat poisoning-lung transplantation. $\mathrm{Br}$ Med $J$ 1984;3: $759-63$.

16 Laithwaite JA. Paraquat poisoning treated with immunosuppresants and potassium aminobenzoate. BMJ 1975;i: 266-7.

17 Vincken W, Huyghens L, Schanderyl W, Verbeeten D, Corne L. Paraquat poisoning and colchicene treatment. Ann Intern Med 1981;95:391-2.

18 Webb DB, Williams MV, Davies BH, James KW. Resolution after radiotherapy of severe pulmonary damage due to tion after radiotherapy of severe pulmonary da
paraquat poisoning. $B M J 1984 ; 288: 1259-60$. 